\title{
ENSINO DA GEOGRAFIA E CARTOGRAFIA SOCIAL: UMA ANÁLISE BIBLIOGRÁFICA DOS ARTIGOS CIENTIFICOS DO 12ํㅡㄴNNT NACIONAL DE PRÁTICAS DE ENSINO EM GEOGRAFIA
}

\author{
Geography Teaching and Social Cartography: the literature review of scientific papers from \\ the $12^{\circ}$ National Meeting of Geography Teaching Practice
}

\author{
Camila Paula de Souza* \\ Ana Paula Melo da Silva ** \\ Liz Cristiane Dias ***
}

\begin{abstract}
* Mestre em Geografia pela UFPEL - camilasouza.geo@gmail.com. ** Discente do Programa de Pós-Graduação em Geografia da UFPEL - anapaulamelogeo@gmail.com. ***Docente do Programa de Pós-Graduação em Geografia da UFPEL - liz.dias@yahoo.com.br.
\end{abstract}

Recebido em 05/08/2018. Aceito para publicação em 25/08/2018.

Versão online publicada em 20/11/2018 (http://seer.ufrgs.br/paraonde)

\begin{abstract}
Resumo:
O presente artigo busca analisar as contribuições teórico-metodológicas da Cartografia Social para o ensino da Geografia, a fim de colaborar para a discussão da temática no âmbito do currículo escolar. Para tanto, utiliza-se como método investigativo a análise de conteúdo dos artigos publicados nos anais da $12^{\circ}$ edição do Encontro Nacional de Práticas de Ensino em Geografia - ENPEG. Com a análise dos artigos desta edição, já ocorrida no ano de 2013 pôde-se perceber que a temática é desenvolvida, porém em um número menor em relação a outras temáticas, e que quando abordada diz respeito a práticas informais não contempladas nos currículos oficiais. Ressalta-se que este artigo é proveniente da pesquisa de dissertação de mestrado desenvolvida no PPGEO/UFPel pela autora principal cujo objetivo, entre outros, é analisar de que forma a Cartografia Social vem sendo ressignificada no espaço escolar.
\end{abstract}

Palavras-chave: Cartografia Social; Ensino da Geografia; ENPEG.

\begin{abstract}
:
The current study sought to analyze the Social Cartography's theoretical and methodological contributions to the teaching of Geography, in order to supplement the discussion of this subject on the school curriculum scope. The method of investigation was performed through the content analysis of the published articles on the Encontro Nacional de Práticas de Ensino em Geografia - ENPEG 12th edition' annals. After analyzing the articles published in the event' edition, held in 2013, it was observed that this subject is little discused, and appears mostly combined with the description of non-formal practices that are not included in official curriculums. It is important to emphasize that this study derives from an ongoing master's thesis' research, developed under the Geography Graduate Program/UFPel, by the main author whose objective, among others, is to analyze how the Social Cartography has been renigmented in the school space.
\end{abstract}

Key-words: Social Cartography; Teaching of Geography; ENPEG.

\section{Introdução}

O presente artigo visa investigar o desenvolvimento da Cartografia Social, enquanto práticas que 
envolvam processos de mapeamentos participativos no Ensino da Geografia, por meio de uma análise documental, e também verificar de que forma essa temática se insere nas discussões sobre um currículo oficial. Vale ressaltar que o objetivo primordial desta pesquisa é evidenciar as práticas escolares que envolvam a Cartografia Social, e por compreender a complexidade deste conceito no qual se relaciona ao Projeto da Nova Cartografia Social da Amazônia ${ }^{1}$.

Para tal, o artigo traz alguns/as autores/as que discorrem sobre o tema e que dão suporte para problematiza-lo no espaço escolar e ressaltar as proximidades existentes em ambos os campos de pesquisa, portanto opta-se por trazer o conceito como resultante de processos de mapeamentos participativos de práticas escolares, no intuito de salientar o fato de que a Cartografia Social ocorre nas escolas e que em alguns casos não é destacada sendo como tal.

A proposta destacada neste artigo ocorre por meio da análise dos artigos do $12^{\circ}$ Encontro Nacional de Práticas de Ensino em Geografia, sendo assim para a realização da metodologia é empregado o método de análise de conteúdo (BARDIN, 2011) para a investigar de que forma ocorre a Cartografia Social nessas práticas escolares descritas nos artigos.

Além disso, o artigo destaca a discussão do currículo para problematizar a Cartografia Social enquanto uma prática associada a um movimento contra-hegemônico, por ser uma forma de cartografar que diverge de uma Cartografia dita cartesiana, ao ter como ponto de partida central da discussão a articulação dos grupos socioespaicias historicamente marginalizados, ao invés de partir de interesses preferencialmente econômicos do Estado, refletindo sobre esse contexto o currículo escolar se aproxima dessa discussão ao ser destacado enquanto um aparelho ideológico do Estado, pois a Cartografia enquanto um instrumento que foi utilizado pelos primórdios Estados-nação tinha como objetivo atender as demandas desses Estados e seus interesses políticos e econômicos.

\section{Desenvolvimento}

No que diz respeito ao contexto escolar que atenda ao modelo de desenvolvimento e interesses do Estado, as escolas servem não apenas para transmitir os conhecimentos, mas também atender a um conhecimento voltado para o mercado de trabalho, de modo que favoreça algumas áreas do conhecimento em detrimento de outras e é nesse aspecto que o currículo se faz como um aparelho ideológico do Estado, ao garantir conteúdos que estejam atrelados a essa demanda do capital. No que concerne a essa discussão Apple (1989), afirma que:

As escolas estão organizadas não apenas para ensinar o "conhecimento referente a quê, como e para quê", exigido pela nossa sociedade, mas estão organizadas também de uma forma tal que elas, ao final das contas, auxiliam na produção do conhecimento técnico/administrativo necessário, entre outras coisas, para expandir mercados, controlar a produção, o trabalho e as pessoas, produzir, a pesquisa básica e aplicada exigida pela indústria e criar necessidades "artificiais" generalizadas entre a população (APPLE, 1989, pg.37).

Dentro dessa discussão a Cartografia Social torna-se um movimento contra-hegemônico pressupondo que a tendência mundial seja a meta pela tecnificação do conhecimento. A Cartografia consolidada como ciência, assume essa categoria ao trazer para discussão sobre a representação espacial aspectos técnicos de processos de mapeamento, em um campo que se articula com o geoprocessamento juntamente com a tecnologia, portanto refletindo sobre o caráter que a Cartografia é expressada no currículo escolar é dentro dessa configuração que a mesma se constitui na disciplina escolar de Geografia.

Sendo assim, é válido ressaltar que a adoção pela perspectiva de uma Cartografia dita cartesiana

\footnotetext{
10 Projeto Nova Cartografia Social da Amazônia (PNCSA) tem como objetivo dar ensejo à auto-cartografia dos povos e comunidades tradicionais na Amazônia. (Fonte: http://novacartografiasocial.com. Acesso em 30/03/2017. Ás 16h30).
} 
é ocasionada em detrimento da negação de outras possíveis formas de se pensar cartograficamente. Partindo-se desse contexto de reflexão sobre os usos da Cartografia, é importante frisar que seu desenvolvimento no espaço escolar está associado a um aparelho ideológico político-social, ou seja, a opção por esse conteúdo reflete à paradigmas de uma sociedade capitalista, e mais além de uma sociedade globalizada, no qual ocorrem tramas que condicionam incentivos a um paradigma a ser seguido que no caso é a tecnificação do conhecimento.

Portanto, a seleção por uma forma de cartografar, negligenciando outras, no currículo escolar legitima-se como sendo apenas um conteúdo escolar, na qual não possuísse uma posição ideológica, ou que fosse uma opção no currículo passível de uma postura ideológica. No que diz respeito a essa reflexão e a um contexto semelhante a estrutura atual da configuração sócio-política, Apple (1989) afirma:

Ao mesmo tempo que a racionalidade processo/produto crescia, o fato de que a educação é, do começo ao fim, um empreendimento político, perdia importância. As questões que fazíamos tendiam a nos divorciar da forma como o aparato econômico e cultural da sociedade funcionava. Um método "neutro" significava nossa própria neutralidade, ou assim nos parecia. 0 fato de que os métodos que empregávamos tinham suas raízes nas tentativas da indústria para controlar os trabalhadores e aumentar a produtividade, nos movimentos de eugenia popular e em grupos com interesses particulares de classe, era obscurecido pela carência extrema de uma visão histórica na área (APPLE, 1989, pg.29).

Retomando a reflexão sobre a escolha em se considerar uma forma de cartografar como única no processo de aprendizagem presente nos currículos oficiais, este vai ao encontro de questões como a negociação pela opção de determinada forma de se fazer Cartografia e não outra. Em consonância ao que Macedo (2006) destaca como no caso da negociação entre culturas num espaço-tempo que contextualizam processos de hegemonização, pode-se também problematizar tal questão em um campo de discussão sobre a adoção de determinada Cartografia no currículo escolar em um espaçotempo que o constitui, a autora afirma que:

(...) o currículo escolar é habitado por uma diferença que não se define como a oposição ao homogêneo, que penso ser possível tratá-lo como uma espécie de espaço-tempo cultural liminar. Um espaço-tempo em que as culturas presentes negociam com "a diferença do outro", que explicita a insuficiência de todo e qualquer sistema de significação (MACEDO, 2006, pg.292).

Mais além, para a contribuição sobre a perspectiva abordada nesse artigo ao tratar sobre currículo, Lopes (2011) disserta que:

Ao optarem por modelos sistêmicos para a definição do que e do como ensinar, tais perspectivas assumem o fazer curricular como questão técnica, científico, ocultando a dimensão sobre o que e o como ensinar não envolvesse disputas ideológicas. A hegemonia dessa visão de currículo elimina um importante aspecto social: a contradição. A crença na harmonia social daí advinda é um importante princípio que oculta as relações de poder e as desigualdades sociais. Em outras palavras pode-se dizer que há currículo oculto a todo currículo organizado segundo os moldes sistêmicos das perspectivas técnicas (LOPES, 2011, pg.32).

O que a autora destaca no trecho anterior vai ao encontro da discussão sobre a escolha de determinados conteúdos no currículo escolar em detrimento de outros, a Cartografia Social por ser um instrumento contra-hegemônico também será impactada em alguns casos por não ser considerada como um conteúdo que esteja diretamente relacionado a uma demanda do capital ou por não ter as bases sistêmicas de uma Cartografia nos moldes cartesianos, porém ao investigar alguns artigos no 12ํㅡㄹ Encontro Nacional de Práticas do Ensino de Geografia foi viável de fazer algumas constatações sobre a relação da Cartografia Social a Educação Geográfica. 


\section{A Cartografia Social na prática escolar: uma discussão conceitual}

O tema ora estudado justifica-se por ser uma discussão atual no campo cientifico cartográfico, porém a hipótese para essa investigação centra-se em averiguar se a Cartografia Social, enquanto prática de mapeamento participativo está também sendo discutida e articulada no espaço escolar. Como já mencionado, o contexto de ação da Cartografia Social se dá pelo seu movimento contrahegemônico, de forma a cartografar elementos pautados de demandas sociais sendo protagonizados por grupos sociais, no intuito de aproximar esse saber cartográfico para utilização dessas pessoas e não sendo um saber somente de âmbito acadêmico.

Nesse sentido, a Cartografia Social destaca elementos que problematizem outras formas de mapear, bem como o empoderamento dos grupos sociais através do saber cartográfico, de forma que sirva como uma estratégia de autonomia para a apropriação e articulação sobre as representações espaciais. Nas palavras de Haesbaert (2014) "todo espaço geográfico é também ação, movimento e representação simbólica", sendo assim, as representações cartográficas oriundas de mapeamentos sociais consideram essa representação simbólica, de forma que o mais relevante seja o processo da construção e discussão desse documento cartográfico orientado por demandas trazidas pelos grupos sociais em questão.

Mais além Massey (2008) complementa que: "Conceituar o espaço como aberto, múltiplo e relacional, não acabado e sempre em devir, é um pré-requisito para que a história seja aberta e, assim, um pré-requisito para a possibilidade da política.". (MASSEY, 2008, pg. 95)

Portanto, trazendo a reflexão de Massey (2008) para o contexto de mapeamento social é possível afirmar que um mapa está sempre em desenvolvimento, levando em consideração que as relações sociais são continuas e estão em fluxos demarcados pelos processos históricos. Contribuindo para essa questão frente as produções de mapeamentos sociais, Girardi (2012), afirma:

Portanto, o mapa nunca está pronto, mas constantemente sendo refeito, ora de modo mais lento, ora de modo mais brusco. O que impulsiona mudanças no mapa são fluxos de intensidades que promovem a desterritorialização, já que, se o território não é o mesmo, o mapa também não pode ser. 0 novo mapa revela uma reterritorialização, que já é territorialização (pois se estabiliza), que pode ser novamente desterritorializada, e assim por diante (GIRARDI, 2012, pg. 40).

Nesse sentido, a produção de mapas sociais poderiam ser consideradas como uma forma de representação da territorialidade, ao propor como estratégia de apropriação territorial as expressões culturais materiais e imateriais dos grupos sociais. E em relação a conceituação de territorialidade, Haesbaert (2014), constata que:

Territorialidade como concepção mais ampla que território, que engloba (a todo território corresponderia uma territorialidade, mas nem toda territorialidade teria, necessariamente, um território - materialmente construído), territorialidade tanto como uma propriedade de territórios efetivamente construídos quanto "condição" (teórica ou simbólica) para a sua efetivação (HAESBAERT, 2014, pg. 65).

Mais além, Acselrad (2010):

Neste processo, o conceito de territorialidade tem se colocado como um elemento central na construção política da identidade dos sujeitos. É nesta trama territorial que comunidades provisórias constituem-se para promover as experiências ditas de "mapeamento participativo" e "cartografia social (ACSELRAD, 2010, pg. 13). 
Portanto, a territorialidade pode se dar de forma simbólica não necessariamente relacionada a um território em questão, mas sim ao imaginário representativo e identitário de um grupo social. E sendo assim, corresponde a uma trama territorial na qual algumas ações sociais se relacionam através da apropriação do espaço. Sobre essa discussão Acselrad (2010) afirma que:

Chamamos aqui de tramas territoriais ao movimento configurado pelos diferentes meios de produção social dos territórios e suas relações constitutivas - por apropriação direta, por instrumentos legais, por projeções identitárias, por mapas e outros meios representacionais (ACSELRAD, 2010, pg.10).

É importante frisar que o reconhecimento de uma prática cartográfica voltada ao desenvolvimento de mapeamentos sociais não é de forma alguma negar o que se consolidou como ciência cartográfica até os dias atuais, mas sim uma forma de complementar a compreensão espacial que não negligencie os sujeitos sociais e suas ações nas representações cartográficas. Um fator que impulsa esta investigação atrela-se a uma noção de espaço absoluto (HARVEY, 2012) que em alguns casos é aparente nos mapas, e essa forma de produção detém de uma narrativa e de uma posição ideológica, que em alguns casos é pontuada como algo que detém de uma neutralidade. Harvey (1973) complementa sobre esse contexto ao afirmar que:

Se considerarmos o espaço como absoluto ele se torna uma 'coisa em si mesma', com uma existência independente da matéria. Ele possui então uma estrutura que podemos usar para classificar ou distinguir fenômenos. A concepção de espaço relativo propõe que ele seja compreendido como uma relação entre objetos que existe pelo próprio fato dos objetos existirem e se relacionarem (HARVEY, 1973, pg.13).

Levando em conta que o mapa deve ser um produto contínuo que está em constante transformação porque se trata de um instrumento que retrata as ações humanas, sendo assim as relações sociais em constante fluxo e circulação, ao relacionar essa reflexão com o espaço escolar se torna ainda mais consistente esse argumento pois, as relações no espaço escolar são ainda mais intensas ao abarcar diferentes faixas etárias e diversos contextos e práticas culturais vivenciados pelos alunos que movimentam e espacializam as relações nas escolas. Tendo em vista esse contexto de análise os mapeamentos sociais na escola são ferramentas potencializadoras ao promover o diálogo com diferentes realidades e indagações no espaço escolar.

\subsection{Encontro Nacional de práticas de Ensino em Geografia}

Considerando a complexidade teórica que está relacionado o conceito de Cartografia Social, o estudo deste artigo tem o intuito de investigar algumas aproximações de conceitos relacionados a este tema no ensino da Geografia, e nesse sentido busca analisar os artigos dos anais publicados no $12^{\mathrm{o}}$ Encontro Nacional de Práticas de Ensino em Geografia, ocorrido no ano de 2013 em João Pessoa Paraíba, tendo este estudo a análise dos artigos, o mesmo se caracteriza como uma análise documental. Segundo Silva (2009):

(...) a pesquisa documental permite a investigação de determinada problemática não em sua interação imediata, mas de forma indireta, por meio do estudo dos documentos que são produzidos pelo homem e por isso revelam o seu modo de ser, viver e compreender um fato social (SILVA, 2009, pg. 4557).

0 propósito de investigar a Cartografia Social no ensino da Geografia é pelo fato dessa temática ocasionar uma ampla dimensão no debate conceitual, visto a sua vasta aproximação com outros conceitos e ferramentas metodológicas. Dessa forma, o interesse em analisar as práticas escolares é destacar de que forma é possível observar a Cartografia Social no âmbito escolar e quais os desdobramentos e conceitos que podem ser evidenciados.

A coleta de dados foi desenvolvida através da análise de conteúdo dos artigos de dois Grupos de

Para0nde!?, Porto Alegre, v.10, n.2, p.45-55, 2018. Edição Especial com artigos publicados originalmente na XII ENANPEGE http://seer.ufrgs.br/paraonde 
Trabalhos (GT's), o GT 4 denominado: "Outras modalidades de ensino de Geografia: aspectos teóricometodológicos"; e o GT 5 denominado: "Linguagens no ensino de Geografia: novas possibilidades". A escolha por esses dois Grupos de Trabalhos se deu pelo fato de abordarem práticas escolares voltadas a repensarem o Ensino da Geografia vista a diversidade de contextos escolares, e nesse aspecto levando em conta o fato de que Cartografia Social é menos expressiva nas discussões do currículo escolar da Geografia do que em práticas de automapeamento em comunidades tradicionais, optou-se em verificar nesses dois GT's se seria possível observar práticas escolares e conceitos relacionados a essa temática.

Sendo assim, para análise dos artigos publicados nesses dois GT's foram estruturados alguns parâmetros através de questões para a realização da fase inicial da análise de conteúdo que corresponde a unitarização dos dados. A seguir é apresentado um quadro com as questões orientadoras da análise:

\section{Quadro I: Perguntas referentes aos parâmetros de análise}

\begin{tabular}{|c|}
\hline Qual o aprofundamento da prática escolar? \\
\hline Qual o nível de ensino é realizada a prática? \\
\hline Quais autores foram utilizados no embasamento teórico? \\
\hline Qual a localização do estudo em âmbito do território nacional? \\
\hline
\end{tabular}

Fonte: Da autora, 2017. essa fase:

Posterior a fase de unitarização foi realizada a categorização dos artigos, segundo Silva (2009),

constitui-se, portanto, como um processo de classificação dos dados. Podem ser definidas previamente quando o pesquisador elege antes da análise as informações a serem procuradas no documento ou ao longo do processo de leitura, seguindo uma perspectiva compreensiva hermenêutica. As categorias devem considerar o material a ser analisado e os objetivos da investigação, procurando atingi-los, responde-los. Podem ser de matérias ou assuntos (temas), de sentido, de valores, de formas de ação, de posicionamento, dentre outras (SILVA, 2009, p. 4561).

A seguir é evidenciado os quadros sínteses da fase de categorização dos dois GT's, em seguida é feita a intersecção das fases destacadas juntamente com a interpretação dos dados, de modo a destacar os objetivos traçados na proposta deste estudo:

Quadro II: Síntese da Análise dos artigos do 12 ENPEG do GT4: Outras modalidades do ensino de Geografia: aspectos teóricos-metodológicos. Ocorrido no ano de 2013

\begin{tabular}{|c|c|c|c|c|}
\hline & $\begin{array}{c}\text { 1. Aprofundamento } \\
\text { prático }\end{array}$ & 2. Nível do ensino & $\begin{array}{c}\text { 3. Autores em } \\
\text { evidência }\end{array}$ & 4. Local \\
\hline Artigo 1 & $\begin{array}{r}\text { Oficina realizada com } \\
\text { os alunos utilizando- } \\
\text { se da Cartografia da } \\
\text { Ação sobre a } \\
\text { degradação } \\
\text { ambiental da Baía de }\end{array}$ & $\begin{array}{c}\text { Quarto e quinto ano } \\
\text { do ensino } \\
\text { fundamental }\end{array}$ & $\begin{array}{c}\text { Milton Santos, Catia } \\
\text { da Silva, Carlos } \\
\text { Walter Porto- } \\
\text { Gonçalves }\end{array}$ & Rio de Janeiro - RJ \\
& & & \\
\hline
\end{tabular}




\begin{tabular}{|c|c|c|c|c|}
\hline & Guanabara (RJ). & & & \\
\hline Artigo 2 & $\begin{array}{c}\text { Oficina pedagógica } \\
\text { com a utilização da } \\
\text { Cartografia Social a } \\
\text { fim de investigar os } \\
\text { problemas } \\
\text { socioambientais da } \\
\text { comunidade Monte } \\
\text { Alvão, localizada em } \\
\text { uma Área de } \\
\text { Preservação } \\
\text { Ambiental, no } \\
\text { distrito de Guará } \\
\text { (PR). }\end{array}$ & $\begin{array}{c}10 \text { alunos do ensino } \\
\text { fundamental e } 10 \\
\text { alunos do ensino } \\
\text { médio }\end{array}$ & $\begin{array}{c}\text { Henri Acselrad, } \\
\text { Marcelo Martinelli, } \\
\text { Denis Richter }\end{array}$ & Guará - PR \\
\hline Artigo 3 & $\begin{array}{c}\text { Intervenção dos } \\
\text { alunos em uma } \\
\text { prática utilizando-se } \\
\text { da Cartografia Social } \\
\text { com a comunidade } \\
\text { Monte Alvo (PR) } \\
\text { para a resolução das } \\
\text { problemáticas } \\
\text { socioambientais. }\end{array}$ & Não informado & $\begin{array}{c}\text { Milton Santos, } \\
\text { Marquiana de } \\
\text { Freitas Vilas Boas } \\
\text { Gomes, David Tripp }\end{array}$ & Guarapuava - PR \\
\hline
\end{tabular}

Fonte: Da autora, 2017.

Quadro III: Síntese da Análise dos artigos do 12 ENPEG do GT 5: Linguagens no ensino de Geografia: novas possibilidades. Ocorrido no ano de 2013

\begin{tabular}{|c|c|c|c|c|}
\hline & $\begin{array}{c}\text { 1.Aprofundamento } \\
\text { prático }\end{array}$ & 2. Nível do ensino & $\begin{array}{l}\text { 3. Autores em } \\
\text { evidência }\end{array}$ & 4. Local \\
\hline Artigo 1 & $\begin{array}{lrr}\text { Aplicação de } & \text { um } \\
\text { questionário } & \text { aos } \\
\text { alunos a fim } & \text { de } \\
\text { investigar } & \text { o } \\
\text { desenvolvimento do } \\
\text { ensino } & \text { de } \\
\text { Cartografia } & \end{array}$ & $\begin{array}{l}\text { Oitavo ano do } \\
\text { ensino } \\
\text { fundamental }\end{array}$ & $\begin{array}{lr}\text { Maria Elena } & \text { Simielli, } \\
\text { Rosangela } & \text { Doin } \\
\text { Almeida, } & \text { Sonia } \\
\text { Castellar } & \end{array}$ & $\begin{array}{c}\text { Bom Conselho - } \\
\text { PE }\end{array}$ \\
\hline Artigo 2 & $\begin{array}{l}\text { Investigação do } \\
\text { Grupo de Estudos: } \\
\text { Dinâmica Ambiental, } \\
\text { Educacional e e } \\
\text { Cultural de pesquisa } \\
\text { na Cartografia } \\
\text { Escolar (UFMA), a } \\
\text { fim de verifiicar } \\
\text { quais os desafios no }\end{array}$ & $\begin{array}{l}\text { Do sexto ao oitavo } \\
\text { ano do ensino } \\
\text { fundamental }\end{array}$ & $\begin{array}{lr}\text { Rosangela } & \text { Doin } \\
\text { Almeida, } & \text { Maria } \\
\text { Elena Simielli, Sonia } \\
\text { Maria } & \text { Munhóes } \\
\text { Romano } & \end{array}$ & Imperatriz - MA \\
\hline
\end{tabular}




\begin{tabular}{|c|c|c|c|c|}
\hline & $\begin{array}{ll}\text { ensino } & \text { de } \\
\text { Cartografia } & \end{array}$ & & & \\
\hline Artigo 3 & $\begin{array}{l}\text { Oficina pedagógica } \\
\text { realizada pela } \\
\text { professora } \\
\text { Geografia na qual os } \\
\text { alunos } \\
\text { representação a sala } \\
\text { de aula através de } \\
\text { um mapa. }\end{array}$ & $\begin{array}{l}\text { Segundo ano do } \\
\text { ensino médio }\end{array}$ & $\begin{array}{lr}\text { Mikail } & \text { Bahktin, } \\
\text { Sonia Castellar, Lana } \\
\text { Cavalcanti, } & \text { John } \\
\text { Harley, } & \text { Gisele } \\
\text { Girardi, } & \text { Marcelo } \\
\text { Martinelli, } & \text { Jorn } \\
\text { Seeman } & \end{array}$ & Campinas - SP \\
\hline Artigo 4 & $\begin{array}{l}\text { Realização de um } \\
\text { atividade prática na } \\
\text { qual os alunos } \\
\text { produziram mapas, } \\
\text { tendo como objetivo } \\
\text { a alfabetização } \\
\text { cartográfica. }\end{array}$ & $\begin{array}{l}\text { Segundo ano do } \\
\text { ensino médio }\end{array}$ & $\begin{array}{lr}\text { Rosangela } & \text { Doin } \\
\text { Almeida, } & \text { Sonia } \\
\text { Castellar, } & \text { Elza } \\
\text { Passini, Nidia } & \text { Nacib } \\
\text { Pontuschka } & \end{array}$ & Rio Grande - RS \\
\hline Artigo 5 & $\begin{array}{lr}\text { Oficina pedagógica } \\
\text { com os alunos em } \\
\text { parceria com } \quad \text { o } \\
\text { PIBID na qual busca- } \\
\text { se identificar } & \text { o } \\
\text { espaço vivido dos } \\
\text { alunos através de } \\
\text { seus mapas }\end{array}$ & $\begin{array}{l}\text { Sétimo ano do } \\
\text { ensino } \\
\text { fundamental }\end{array}$ & $\begin{array}{l}\text { Yves Lacoste, Elza } \\
\text { Passini, Moreira e } \\
\text { Brito Salvador, } \\
\text { Geraldo José Ballone }\end{array}$ & Londrina - PR \\
\hline Artigo 6 & $\begin{array}{l}\text { Investigação teórica } \\
\text { dos mapas } \\
\text { desenvolvidos pelos } \\
\text { alunos no projeto de } \\
\text { extensão } \\
\text { universitária } \\
\text { intitulado: "1001 } \\
\text { mapas de Barbalha: } \\
\text { alunos das escolas } \\
\text { públicas } \\
\text { representam seu } \\
\text { lugar" }\end{array}$ & Não informado & $\begin{array}{l}\text { Angela Katuta, Elza } \\
\text { Passini, r Denis } \\
\text { Richter, Jorn Seeman }\end{array}$ & Barbalha - CE \\
\hline Artigo 7 & $\begin{array}{lr}\text { Investigação teórica } \\
\text { sobre } & \text { algumas } \\
\text { reflexões res } & \text { de } \\
\text { metodologias } & \text { no } \\
\text { desenvolvimento } & \text { da } \\
\text { linguagem } & \end{array}$ & Não informado & $\begin{array}{lr}\text { Rosangela } & \text { Doin } \\
\text { Almeida, } & \text { Angela } \\
\text { Katuta, Maria Elena } \\
\text { Simielli, } \\
\text { Oliveira }\end{array}$ & São Paulo - SP \\
\hline
\end{tabular}




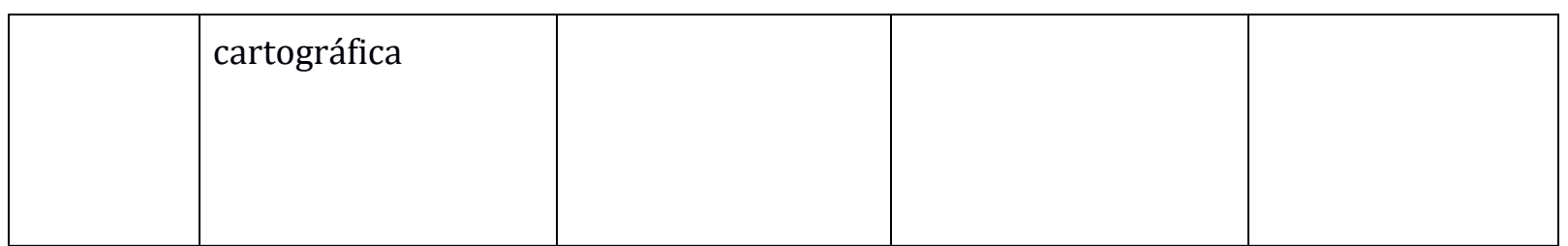

Fonte: Da autora, 2017.

Pela análise observada nos dois GT's do ENPEG em relação aos locais em que são desenvolvidas as práticas escolares, percebeu-se que estas concentram-se na região sul com o maior número de artigos no estado do Paraná. Também verificou-se que nessas práticas a questão ambiental no ensino de Geografia merece destaque e está atrelada a um conhecimento mais analítico do contexto social dos alunos e dos conteúdos geográficos, nesse sentido Bortolozzi e Filho (2000) problematizam sobre a função da Educação Ambiental e apontam para:

uma visão de mundo global, na qual o homem não se separe da natureza e que, portanto, a questão ambiental não esteja separada das questões sociais mais amplas, que compreenda a questão ambiental como a interligação e interdependência entre os fenômenos sociais, físicos, econômicos, biológicos, culturais e políticos (BORTOLOZZI; FILHO, 2000, p.147).

No que tange a análise no nível de ensino é possível verificar que há uma concentração das práticas escolares no ensino fundamental, no recorte do 4으 ao 8o do Ensino Fundamental, verificou-se em dois artigos práticas realizadas no $2^{\circ}$ ano do Ensino Médio. Sendo assim, esses dados vão ao encontro sobre o que prescrevia a proposta curricular nos livros didáticos sobre compreensão da Linguagem Cartográfica, por exemplo nos anos finais do Ensino Fundamental, desenvolvida na disciplina de Geografia. Por esse ângulo, Castellar (2011) esclarece que:

a linguagem cartográfica torna-se uma metodologia inovadora na medida em que permite relacionar conteúdos, conceitos e fatos; permite a compreensão, pelos alunos, da parte e da totalidade do território, e está vinculada a valores de quem elabora ou lê o mapa (CASTELLAR, 2011, p. 122).

Para a autora, a Linguagem Cartográfica proporciona aos alunos um conhecimento analítico do espaço geográfico, de modo a relacionar os conceitos da Geografia ao seu contexto local através da elaboração dos mapas, o que também é aparente nas práticas desenvolvidas nos artigos analisados.

Outra questão que merece destaque, diz respeito a observância nos artigos supradescritos das categorias de análise geográfica como elementos centrais para o desenvolvimento das metodologias, de modo a relacionar essas categorias com o contexto local dos alunos. Uma categoria de análise evidente nas práticas escolares desenvolvidas nos artigos foi o Lugar, de modo a reafirmar sobre a relação da Geografia no contexto de vivência dos alunos.

Ademais, foi notável, com base nos parâmetros estabelecidos, que existe uma produção científica citada nos artigos desses dois GT's que aborda a temática da Cartografia Social, porém o que se percebe é que em algumas das práticas descritas nos artigos, que utilizam metodologias que se aproximam da Cartografia Social e dos mapeamentos participativos, não se definem conceitualmente como práticas oriundas deste contexto. A ênfase em destacar essas práticas que vão ao encontro de uma proposta de Cartografia Social não se direciona em uma rotulação, mas sim em uma reflexão sobre práticas escolares que estão utilizando de metodologias diversificadas, e que não atribuem a construção de mapas tão somente como um objeto estanque e distante da realidade dos alunos.

Diante disso, o que pode-se admitir é que alguns professores e pesquisadores da Geografia vem desenvolvendo práticas relacionadas a mapeamentos participativos, que se justificam a partir do arcabouço teórico-metodológico da Cartografia Social, porém não é utilizada essa conceituação nas metodologias desenvolvidas. Esse fato, reforça a relação da Cartografia Social tão somente com as pesquisas etnográficas, o que torna a mesma distante do espaço escolar. 


\section{Considerações Finais}

Tendo em vista a complexidade das temáticas abordadas e a dimensão dos elementos subjetivos que compõe o assunto destacado, a reflexão acerca da análise de dados se torna substancialmente difícil. Nessa sentido, ocorre um estado de inconclusão que condiciona o necessário avanço epistemológico e teórico, ainda mais se tratando do conceito de Cartografia Social que coloca o debate acadêmico em um movimento constante, levando em consideração o fato deste conceito não ser "fechado" pela comunidade geográfica.

Pelo que foi abordado anteriormente é plausível afirmar que de forma geral existe uma produção científica nos artigos analisados desses dois GT’s que tratam sobre a temática da Cartografia Social, porém o que se pode notar é que muitas das práticas que são descritas nos artigos que utilizam metodologias de mapeamentos participativos, acabam por descrevê-las não como sendo práticas de Cartografia Social, e sim como práticas de Cartografia tão somente.

0 que se pode admitir deste dado é que alguns professores e pesquisadores de Geografia vem desenvolvendo práticas relacionadas a mapeamentos participativos, que em sua estruturação teórica se conceituam como Cartografia Social, porém não é utilizado essa conceituação nas metodologias desenvolvidas.

Portanto, perante essa análise é notável que existe uma relação da Cartografia Social em âmbito escolar, no que tange as práticas que foram destacadas nos artigos, o que se nota é que existe um limite de diferenciação e de contextualização epistemológica entre a Cartografia Social discutida em âmbito acadêmico e uma outra pouco discutida no espaço escolar.

Todavia, na prática essa aproximação já ocorre, porém no debate epistemológico ainda necessita estreitar a discussão. Além disso, cabe salientar que a Cartografia Social não é argumentada neste artigo como a solução para as várias problemáticas enfrentadas no âmbito escolar, mais especificamente na disciplina de Geografia, porém como observada nas práticas descritas nos artigos, ela pode ser uma ferramenta metodológica para lidar com as múltiplas relações vividas pelos alunos no mundo contemporâneo e, principalmente ser um instrumento potencializador que traga pautas para discussões atuais para além do espaço escolar.

\section{Referências}

ACSELRAD, H. Cartografia social e dinâmicas territoriais: marcos para o debate. Acserald (organizador): Aurélio Vianna Jr (et al.). - Rio de Janeiro: Universidade Federal do Rio de Janeiro, Instituto de Pesquisa e Planejamento Urbano e Regional, 2010. 225 p.

APPLE, M. Educação e Poder. Tradução: Maria Cristina Monteiro. - Porto Alegre: Artes Médicas 1989. $201 \mathrm{p}$.

BORTOLOZZI, A; FILHO, A. Diagnóstico da Educação Ambiental no Ensino de Geografia. Cadernos de Pesquisa, no 109, março/2000.

CASTELLAR, S; VILHENA, J. Ensino de Geografia. São Paulo: Cengage Learning, 2010. - (Coleção Ideia em Ação/ coordenadora Anna Maria Pessoa de Carvalho.

BARDIN, L. Análise de conteúdo. tradução Luís Antero Reto, Augusto Pinheiro. - São Paulo: Edições 70, 2011.

GIRARDI, G. Mapas alternativos e educação geográfica. Revista Percursos. Florianópolis, v.13, n.2, pp.39 - 51, jul./dez.2012.

HAESBAERT, R. Viver no limite: território e multi/transterritorialidade em tempos de in-segurança e contenção. 1. Ed. - Rio de Janeiro: Bertrand Brasil, 2014. 320 p. 
HARVEY, D. 0 espaço como palavra-chave. In: CASTREE, N.; GREGORY, D. (org.). David Harvey: a critical reader. Malden e Oxford: Blackwell. Tradução livre: Letícia Gianella. Texto publicado no v. 14, n. 28 (2012) da revista GEOgraphia (do Programa de Pós-Graduação em Geografia, da Universidade Federal Fluminense) e cedido para esta edição da Em Pauta: teoria social $e$ realidade contemporânea.

Social justice and the city. Londres: Edward Arnold e Baltimore; John Hopkins University Press. 1973.

LOPES, A. MACEDO, E. Teorias de currículo. São Paulo: Cortez, 2011.

MACEDO, E. Currículo como espaço-tempo de fronteira cultural. Rev. Bras. Educ., Ago 2006, vol.11, no.32, p.285-296.

MASSEY, D. Pelo Espaço: uma nova política da espacialidade. Rio de Janeiro: Bertrand, 2008. 312 p.

SILVA, L. et al. Pesquisa documental: alternativa investigativa na formação docente. In: CONGRESSO NACIONAL DE EDUCAÇÃO - EDUCERE, IX, ENCONTRO SUL BRASILEIRO DE PSICOPEDAGOGIA, III, 2009, Curitiba. 